\title{
Papillary, Follicular, Hurthle Cell, Poorly Differentiated, and Anaplastic Thyroid Carcinoma pT4a TNM Finding v8
}

National Cancer Institute

\section{Source}

National Cancer Institute. Papillary, Follicular, Hurthle Cell, Poorly Differentiated, and Anaplastic Thyroid Carcinoma pT 4a TNM Finding v8. NCI Thesaurus. Code C140923.

Gross extrathyroidal extension invading subcutaneous soft tissues, larynx, trachea,

esophagus, or recurrent laryngeal nerve from a tumor of any size. (from AJCC 8th Ed.) 